\title{
Challenge to Promote Change: The Neural Basis of the Contextual Interference Effect in Young and Older Adults
}

\author{
니sa Pauwels, ${ }^{1 \star}$ Sima Chalavi, ${ }^{1 \star}$ Jolien Gooijers, ${ }^{1}{ }^{\circledR C}$ Celine Maes, ${ }^{1}$ Geneviève Albouy, ${ }^{1}$ Stefan Sunaert, ${ }^{2}$ \\ and Stephan P. Swinnen ${ }^{1}$ \\ ${ }^{1}$ KU Leuven, Movement Control and Neuroplasticity Research Group, Department of Movement Sciences, Group Biomedical Sciences, 3001 Leuven, \\ Belgium and ${ }^{2} \mathrm{KU}$ Leuven and University Hospital Leuven, Translational MRI and Radiology, Department of Imaging and Pathology, Group Biomedical \\ Sciences, 3000 Leuven, Belgium
}

Motor performance deteriorates with age. Hence, studying the effects of different training types on performance improvement is particularly important. Here, we investigated the neural correlates of the contextual interference (CI) effect in 32 young (YA; 16 female) and 28 older (0A; 12 female) human adults. Participants were randomly assigned to either a blocked or a random practice schedule, practiced three variations of a bimanual visuomotor task over $3 \mathrm{~d}$, and were retested $6 \mathrm{~d}$ later. Functional magnetic resonance imaging data were acquired during the first and last training days and during retention. Although the overall performance level was lower in OA than YA, the typical CI effects were observed in both age groups, i.e., inferior performance during acquisition but superior performance during retention for random relative to blocked practice. At the neural level, blocked practice showed higher brain activity in motor-related brain regions compared with random practice across both age groups. However, although activity in these regions decreased with blocked practice in both age groups, it was either preserved (YA) or increased $(\mathrm{OA})$ as a function of random practice. In contrast, random compared with blocked practice resulted in greater activations in visual processing regions across age groups. Interestingly, in $0 \mathrm{~A}$, the more demanding random practice schedule triggered neuroplastic changes in areas of the default mode network, ultimately leading to better long-term retention. Our findings may have substantial implications for the optimization of practice schedules, and rehabilitation settings in particular.

Key words: aging; contextual interference; default mode network; fMRI; motor skill learning

\section{Significance Statement}

In aging societies, it is critically important to understand how motor skills can be maintained or enhanced in older adults, with the ultimate goal to prolong functional independence. Here, we demonstrated that a more challenging random as opposed to a blocked practice environment temporarily reduced performance during the acquisition phase but resulted in lasting benefits for skill retention. In older adults, learning success was critically dependent on reduction of activation in areas of the default mode network, pointing to plastic functional changes in brain regions that are vulnerable to aging effects. The random practice context led to increased economy of brain activity and better skill retention. This provides new perspectives for reversing the negative consequences of aging.

\section{Introduction}

When learning motor skills, it is crucial to know which type of organization of training leads to the best possible outcome. In

\footnotetext{
Received Sept. 14, 2017; revised Jan. 26, 2018; accepted Feb. 16, 2018.

Author contributions: L.P., S.C., J.G., C.M., G.A., S.S., and S.P.S. designed research; L.P., S.C., C.M., and S.S. performed research; L.P., S.C., J.G., G.A., and S.P.S. analyzed data; L.P., S.C., J.G., C.M., G.A., and S.P.S. wrote the paper.

This work was supported by grants from the Research Program of the Research Foundation-Flanders [Fonds Wetenschappelijk Onderzoek (FW0); http://www.fwo.be/; Grant G089818N), Excellence of Science (Grant 30446199, MEMODYN), and the Research Fund of KU Leuven, Belgium (Grant C16/15/070). L.P. was supported by an aspirant fellowship from the Research Foundation-Flanders (FW0). The funders had no role in study design, data collection and analysis, decision to publish, or preparation of this manuscript. We thank René Clerckx for programming the task and for technical assistance.
}

this respect, random practice refers to training subtasks in random order (A, C, B, C, A, B...) and blocked practice to training in consecutive order (AA...; BB...; CC...). Even though random practice is detrimental to performance during the acquisition phase, it eventually leads to better long-term retention, an effect

*L.P. and S.C. contributed equally to this work.

The authors declare no competing financial interests.

Correspondence should be addressed to Stephan P. Swinnen, Motor Control Laboratory, Movement Control and Neuroplasticity Research Group KU Leuven, Tervuurse Vest 101, Building De Nayer, Room 02.11, 3001 Leuven, Belgium. E-mail: Stephan.Swinnen@kuleuven.be.

DOI:10.1523/JNEUROSCI.2640-17.2018

Copyright $\odot 2018$ the authors $\quad 0270-6474 / 18 / 383333-13 \$ 15.00 / 0$ 
called contextual interference (CI; Shea and Morgan, 1979). Despite its well documented behavioral benefits, the neural basis of the CI effect is still poorly understood.

Two accounts have been proposed to explain the CI effect. The elaboration hypothesis posits that the blocked group engages in "intratask" processing with little opportunity to reference to other task variants. Random practice, however, facilitates a high level of "intertask" processing, resulting in a more elaborate/distinctive memory representation (Shea and Morgan, 1979; Shea and Zimny, 1983). In contrast, the action-plan reconstruction hypothesis implies that the interleaved nature of random practice forces forgetting of task-specific information of previously encoded action plans, requiring the learner to generate the next action plan anew. This leads to stronger memory traces that benefit retention performance. No reconstruction is needed during blocked practice as the same action plan can be used repeatedly (Lee and Magill, 1983, 1985). Even though the neural signatures of these hypotheses have not been identified so far, one can assume that random practice would require more neural resources (reconstruction), including more elaborate sensory processing engagement for intertask comparison (elaboration).

Cross et al. (2007) reported that from the early to late phase of learning, random relative to blocked practice showed increased activity in premotor and motor cortices during movement preparation and increased activity within the executive function circuitry during task execution. Others demonstrated higher activity in the frontoparietal network [including premotor cortex $(\mathrm{PM})$, primary motor cortex (M1), and posterior parietal cortex (PPC)] during random compared with blocked practice during task execution (Wymbs and Grafton, 2009; Lin et al., 2011). Interestingly, whereas increased dorsolateral-prefrontal cortex (DLPFC) activity during the acquisition phase was associated with the $\mathrm{CI}$ retention benefit in young adults (YA), increased activity in sensorimotor regions was associated with the CI retention benefit in older adults (OA; Lin et al., 2012), suggesting age-related alteration of neural activation. In summary, it is not surprising that higher frontoparietal activity was found for random versus blocked practice because this is a typical signature of sequence task learning paradigms that have dominated this field (Doyon et al., 2003). Accordingly, whether these differential brain activation patterns are task specific or reflect a genuine feature of the distinct practice contexts and how these patterns are modulated during learning and retention (retrieval) remains unresolved.

Here, we investigated the neural basis of the CI effect in YA and $\mathrm{OA}$ using a bimanual visuomotor tracking task. Functional magnetic resonance imaging (fMRI) data were collected over two training sessions and a retention test. We examined (1) whether blocked versus random practice induces different patterns of brain activity during the acquisition phase and how these activations change from the early to late phase of learning within each age group and (2) whether different neural substrates are involved during skill retrieval at delayed retention (DR) as a function of practice schedule and age. The more challenging random practice context was hypothesized to lead to higher recruitment of regions associated with bimanual task planning and execution (action-plan reconstruction hypothesis) and more involvement of sensory processing regions for enhanced intertask comparison (elaboration hypothesis). Since a visuomanual tracking task was used, higher activity in visual processing and integration regions was expected, particularly in the middle temporal region (MT/V5+), as shown previously during performance of similar bimanual skills with enhanced visual feedback (Debaere et al., 2003; Beets et al., 2015). Furthermore, sustained activity in these
Table 1. Group information

\begin{tabular}{llll}
\hline & & \multicolumn{2}{l}{ Mean \pm SD } \\
\cline { 3 - 4 } Group & Number of participants & Age (years) & MoCA \\
\hline YA-blocked & 16 (8 female) & $22.1 \pm 2.2$ & $28.4 \pm 1.4$ \\
YA-random & 16 (8 female) & $21.4 \pm 1.2$ & $28.3 \pm 1.4$ \\
OA-blocked & 14 (6 female) & $66.2 \pm 4.3$ & $27.3 \pm 1.9$ \\
OA-random & 14 (6 female) & $66.8 \pm 3.9$ & $28.1 \pm 2.0$ \\
\hline
\end{tabular}

visual processing regions was expected during skill retrieval following random practice, supporting their role in subtask memory consolidation. With respect to aging, putting forward specific hypotheses regarding modulation in brain activity during acquisition and skill retrieval following different practice schedules is challenging because current evidence is fragmented at best. Nevertheless, we were particularly interested in identifying patterns of cortical hyperactivation in older adults, including deficits in deactivation of brain areas not relevant for task performance (Santos Monteiro et al., 2017).

\section{Materials and Methods Participants}

A total of 60 participants, of which 32 were YA (mean age, $21.8 \pm 1.8$ years; range, $18-27$ years) and 28 were OA (mean age, $66.5 \pm 4.1$ years; range, 60-74 years), took part in the experiment. Within each age group, participants were randomly assigned to either of two CI practice conditions: (1) blocked practice and (2) random practice. As such, four different groups were tested: YA-blocked, YA-random, OA-blocked, and OA-random. Detailed group information can be found in Table 1 . There were no between-condition differences with respect to age (YA group, $p=0.290$; OA group, $p=0.716$ ). None of the participants had a history of neurological or psychiatric disorders. Handedness was assessed using the Oldfield Handedness scale (Oldfield, 1971), and laterality scores did not differ between practice conditions within each age group (YA group, $p=0.478$; OA group, $p=0.103$ ). In addition, the Montreal Cognitive Assessment (MoCA) test was conducted to screen for mild cognitive impairment. MoCA scores did not differ between practice schedule conditions within each age group (YA group, $p=0.800$; OA group, $p=$ $0.303)$. Participants were blind to the purpose of the experiment. Before testing, written informed consent was obtained from each participant. The protocol was approved by the local ethical committee of KU Leuven, Belgium, and was in accordance with the Declaration of Helsinki (1964).

\section{Overview of experimental sessions}

Each participant followed a training protocol consisting of five sessions in total (for an overview of the study protocol, see Fig. 1). During the first session (DAY0), participants were carefully screened for handedness (Oldfield, 1971), cognitive performance (MoCA), and contra-indication to MRI. This was followed by a baseline test in a dummy scanner during which participants performed a bimanual visuomotor tracking task. DAY0 was followed by $3 \mathrm{~d}$ of practice, i.e., DAY1, DAY2, and DAY3. For practical reasons, DAY1 and DAY2 were consecutive days whereas there was $1 \mathrm{~d}$ of rest between DAY2 and DAY3. The first (DAY1) and the last (DAY3) days of practice were conducted in the actual MRI scanner, whereas the second day (DAY2) was performed in the dummy scanner. Finally, a DR test was administered in the actual MRI scanner $6 \mathrm{~d}$ after the last day of practice.

\section{Behavioral procedure}

\section{Instrumentation and task description}

Participants laid in a supine position on the extendible table of the actual MRI or dummy scanner. The task device, a non-ferromagnetic apparatus with two dials (diameter $=5 \mathrm{~cm}$ ) for movement recording, was positioned over the participants' legs and fixated in the lateral ramps of the MRI table (Fig. 2A). The dials could be adjusted to the participants' anthropometry and had an angle of $\sim 45^{\circ}$ for comfortable handling. To prevent excessive head movements during task performance, foam 

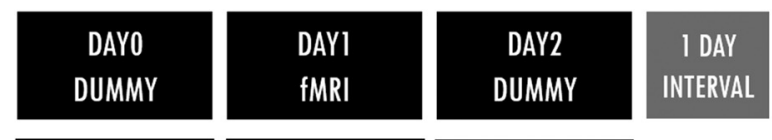

\begin{tabular}{c}
\hline $4 \min$ \\
BASELINE \\
1 block \\
NFB \\
\hline
\end{tabular}

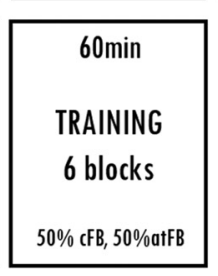

ACQUISITION PHASE
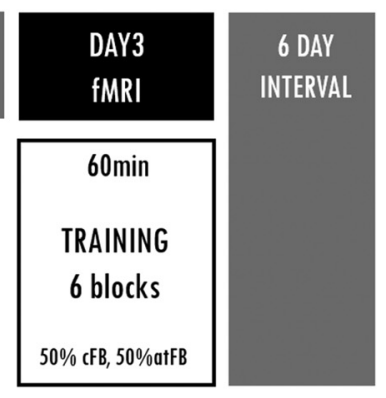

DELAYED RETENTION (DR)
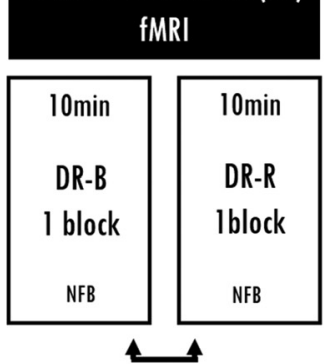

COUNTERBALANCED

Figure 1. Overview of experimental sessions. Each participant completed a training protocol consisting of a baseline session (DAY0), $3 \mathrm{~d}$ of practice (DAY1, DAY2, and DAY3) and a DR test. DR consisted of a blocked (DR-B) and random (DR-R) test, which was counterbalanced across participants. Whereas no feedback was provided during DAY0 and DR, a feedback protocol in which $50 \%$ of the trials were provided with cFB and $50 \%$ of the trials with atFB was used during the training sessions. To assess task-related brain activity, fMRI was acquired during early (DAY1) and late (DAY3) phases of acquisition as well as during DR.

A

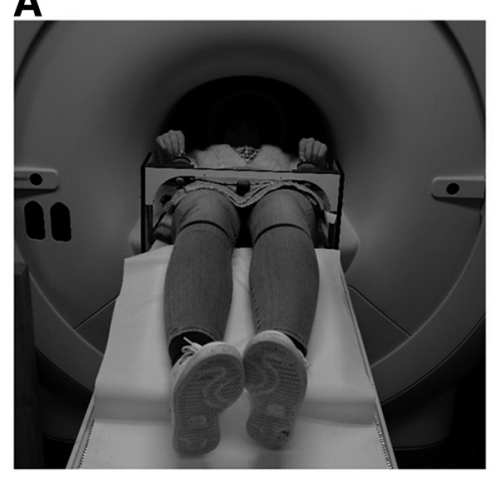

B

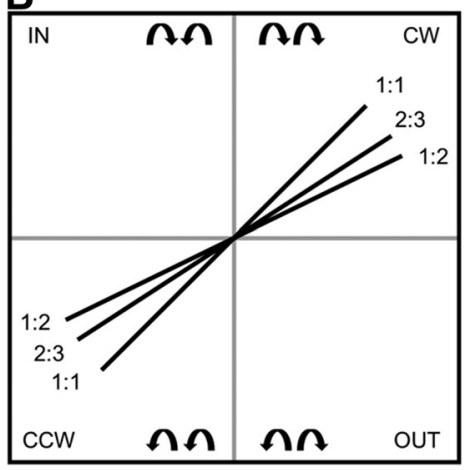

Figure 2. $\quad A$, Experimental setup in the (dummy or actual) scanner. Participants lay in a supine position on the table of the MRI or dummy scanner with the task device positioned over the participants' upper legs. $\boldsymbol{B}$, All possible bimanual directional combinations $(n=2)$ and frequency ratios $(n=3)$. Schematic representation of the target lines presented into two possible coordination directions (CW and $\mathrm{CCW}$ ) and three frequency ratios (1:1, 2:3, and 1:2).

cushions were placed around the participant's head. Visual stimuli were displayed by means of an LCD projector (Barco 6300, $1280 \times 1024$ pixels) onto a double mirror placed in front of the participant's eyes. Participants were instructed to produce a set of complex bimanual coordination patterns, requiring rotational movements of both hands simultaneously. Movements were made by manually turning the handle of the dials. Angular displacements were registered by means of nonferromagnetic high-precision optical shaft encoders (2048 pulses per revolution; sampling frequency, $100 \mathrm{~Hz}$ ), fixed to the movement axes of both dials. This enabled registration of kinematics as well as displaying on-line visual information.

The task was similar to the one used by Pauwels et al. $(2014,2015)$. The aim was to follow a white target dot along a blue target line on the screen. To perform the required movement, participants rotated both dials simultaneously by holding each handle between the thumb and index finger. During feedback trials, a yellow cursor showed the current position so that the deviation from the target dot could be corrected. The left dial controlled the vertical component of the participant's cursor, such that when turning it clockwise, the cursor moved up and when turning it counterclockwise, the cursor moved down. The right dial controlled the horizontal component of the participant's cursor, such that when turning the dial clockwise or counterclockwise, the cursor moved right or left, respectively.

A blue target line indicated the main coordination directions: the two hands could rotate clockwise (CW), counterclockwise (CCW), inward (IN), or outward (OUT; Fig. 2B). The latter two coordination directions were not used in the current training protocol; however, they were used for the instructions given before testing to maximize understanding of the rules of the task. Each coordination direction could be performed at different frequency ratios, which were visualized by the slope of the target line (Fig. 2B). A target line with a $45^{\circ}$ slope indicated a 1:1 frequency ratio, whereby both hands were required to rotate at equal speeds. We used the convention of referring to the left hand first and the right hand second, i.e., L:R. For example, a 1:2 frequency ratio required the right hand to move twice as fast as the left hand. In this study, coordination direction (CW and CCW) and frequency ratios (1:1, 2:3, and 1:2) were used to provide an extra dimension of complexity to the task during learning.

Three different types of feedback conditions were used to prevent reliance on feedback and to optimize learning (Kovacs and Shea, 2011; Pauwels et al., 2014, 2015): concurrent visual feedback (cFB), after-trial feedback (atFB), and no feedback (NFB; Fig. $3 A$ ). In all conditions, the blue target line and the white target dot were presented. The white target dot was first covered by a yellow cue that indicated whether feedback would be given in the upcoming trial. The cue and target dot remained motionless in the center of the screen for $2 \mathrm{~s}$. No movement was required, but the subject was instructed to plan the movement (planning phase). When the yellow cue disappeared, the execution phase started and lasted $9 \mathrm{~s}$. During the execution phase, the white target dot moved with constant speed starting from the center of the display, along the blue target line, toward the periphery. The goal of each trial was to closely track the target line by turning the two dials in the proper direction and to control the relative velocity between the two hands such that the correct frequency ratio could be produced. The intertrial interval lasted $3 \mathrm{~s}$ in which a black screen was presented. In the $\mathrm{cFB}$ condition, current performance was visualized on-line by a yellow cursor that contained the most recent information of the participants' movement track ( $1 \mathrm{~s})$, upon which movements could be corrected. During atFB trials, no yellow cursor was shown, and only the blue target line and the white target dot were presented. Feedback was provided immediately after each atFB trial (with a total duration of $1 \mathrm{~s}$ ) by presenting a motionless representation of a participant's produced line, along with the target line, indicating the discrepancy between the produced and the required movement. This atFB line consisted of green and red parts, indicating whether the relative velocity between the two hands was correct (i.e., either on or parallel with the target line), or not, respectively. In NFB trials, the blue target line and the moving white target dot were also presented, but neither cFB nor atFB was provided. Thus, in both the atFB and NFB conditions, participants were required to track the target pathway without concurrent visual guidance.

We also included no-move trials to provide a baseline measure for the fMRI analyses. Instead of a yellow cue, no-move trials were preceded by 
a pink cue (Fig. 3B). The order of the no-move trials was semirandomized, and they were included in each task block in a way that onethird of a block consisted of no-move trials. This was also the case during the sessions inside the dummy scanner (DAY0 and DAY2) to keep experimental settings as similar as possible.

\section{Experimental design}

The behavioral design used in the current experiment was similar to the one used by Pauwels et al. (2014). Participants learned three different frequency ratios $(1: 1,2: 3$, and 1:2) in two coordination directions (CW, CCW), i.e., six different trial types over 3 practice days within 1 week. The six trial types were trained either under a blocked or a random practice schedule.

Baseline (DAY0). Before testing, participants were informed about the basic requirements to perform the task, i.e., knowledge of the different directions and their associated rotations (CW, CCW, IN, and OUT). No information was given on how to produce the different frequency ratios. To assess whether every subject understood the basic requirements of the task, a familiarization block consisting of four trials, i.e., a 1:1 frequency ratio in each coordination direction (CW, CCW, IN, and OUT), was conducted. To assess baseline performance, i.e., without prior practice of the to-be-trained trial types, participants performed 12 NFB move trials, i.e., four trials per frequency ratio. Frequency ratios during baseline were presented in a blocked manner; however, this was counterbalanced across participants (cfr. three different practice orders used in the acquisition phase). Only NFB trials were presented to prevent learning from on-line visual or after-trial feedback.

Acquisition phase (DAY1-DAY2-DAY3). The acquisition phase took $3 \mathrm{~d}$. Participants in the blocked condition trained one frequency ratio per day. In this condition, the order of the trained frequency ratios was counterbalanced over practice days following one of three practice orders on DAY1, DAY2, and DAY3, respectively; practice order 1 was $1: 1,2: 3$, and 1:2; practice order 2 was 1:2, 1:1, and 2:3; practice order 3 was $2: 3,1: 2$, and $1: 1$. Within each practice day, each frequency ratio was first trained in the CW direction (blocks 1-3) before being trained in the CCW coordination direction (blocks 4-6). Each block contained 24 moving trials, and $1 \mathrm{~min}$ of rest was provided between blocks. Participants in the random condition were exposed to all three frequency ratios (in two coordination directions) following a randomized order during every block, i.e., eight trials per frequency ratio in each block, of each practice day. The number of practice trials for every frequency ratio was equal for the two $\mathrm{CI}$ conditions. At the end of practice, a total of 432 move trials were completed, of which $50 \%$ were with cFB and $50 \%$ were with atFB. The reason behind implementation of atFB trials during practice was to optimize learning and to prevent reliance on concurrent visual feedback, as the retention test was conducted without any visual guidance (see also Pauwels et al., 2014, 2015). Approximately 60 min were needed to finish six practice blocks ( 1 practice day). For an overview of the acquisition phase, see Figure 4.

Delayed retention. Six days after the last day of practice (DAY3), participants came back for a DR test to assess the practiced frequency ratios.
Two retention schedules, i.e., blocked DR (DR-B) and randomized DR (DR-R), were used in both practice schedule groups to ensure that acquisition-retention compatibility was similar for the two CI conditions. Both the DR-B and DR-R consisted of 24 NFB move trials, i.e., eight trials per frequency ratio. Therefore, a total of 48 move and 24 no-move trial scans were acquired during DR. The order of DR-B and DR-R was counterbalanced. Additionally, the order in which frequency ratios appeared in DR-B was counterbalanced according to one of the three practice orders mentioned above. During DR-R, the trained coordination patterns were presented randomly. DR-B and DR-R runs each took $10 \mathrm{~min}$ to complete. During both retention blocks, only NFB trials were presented to participants to prevent learning from on-line visual feedback or after-trial feedback.

\section{Imaging procedure}

A Philips Achieva 3-T magnetic resonance scanner (Philips Healthcare) with a 32-channel head coil was used. Three-dimensional T1-weighted images [magnetization prepared rapid gradient echo; time repetition/ 


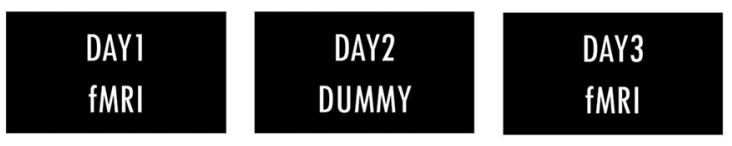

\begin{tabular}{|c|c|c|c|}
\hline \multicolumn{3}{|c|}{ BLOCKED PRACTICE SCHEDULE* } & \\
\hline Blockl-6 & Blockl-6 & Blockl-6 & $6 \times$ (24 move + \\
\hline $1: 1$ & $2: 3$ & $1: 2$ & 12 no-move \\
\hline $\begin{array}{c}\text { FREQUENCY } \\
\text { RATIO }\end{array}$ & $\begin{array}{c}\text { FREQUENCY } \\
\text { RATIO }\end{array}$ & $\begin{array}{c}\text { FREQUENCY } \\
\text { RATIO }\end{array}$ & $\begin{array}{l}\text { each day of } \\
\text { practice }\end{array}$ \\
\hline
\end{tabular}

RANDOM PRACTICE SCHEDULE

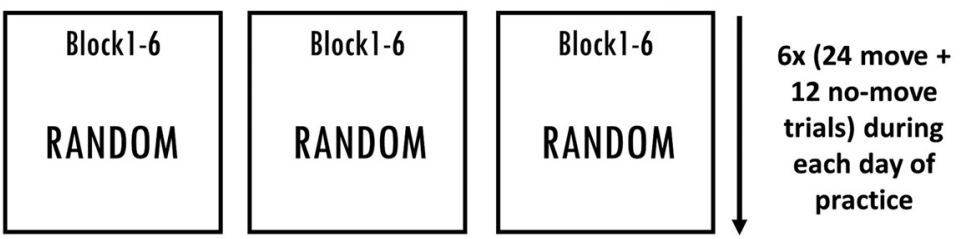

* Frequency ratios were counterbalanced over practice days

Figure 4. Blocked and random training schedules. Participants following blocked practice trained one frequency ratio per day, whereas participants following random practice were exposed to all three frequency ratios (following a random practice order) during each block of each practice day. Each practice day consisted of six blocks, each including 24 move and 12 no-move trials. The number of practice trials for each frequency ratio was identical for blocked and random practice groups.

time echo (TR/TE), $9.6 \mathrm{~ms} / 4.6 \mathrm{~ms} ; 0.98 \times 0.98 \times 1.2 \mathrm{~mm}$ voxel size; field of view, $192 \times 250 \times 250$; 160 coronal slices; scan time, $\sim 7 \mathrm{~min}]$ were acquired for image registration of fMRI runs. Next, a field map was acquired to address local distortions. While participants were performing the bimanual coordination task on DAY1 (six runs), DAY3 (six runs), and DR (two runs), functional images were acquired. The fMRI runs consisted of 41 ascending gradient echo planar images (EPIs) for T2weighted functional images (TR/TE, $3000 \mathrm{~ms} / 30 \mathrm{~ms}$; flip angle, $90^{\circ} ; 54$ parallel axial slices with a slice thickness of $2.5 \mathrm{~mm}$; interslice gap, 0.2 $\mathrm{mm}$; in-plane resolution, $2.5 \times 2.5 \mathrm{~mm} ; 82 \times 84$ matrix). Each fMRI run took almost $10 \mathrm{~min}$ and consisted of 24 move and 12 no-move trials.

\section{Analysis}

\section{Behavioral analysis}

Dependent measures. Behavioral data were recorded and analyzed with Labview (version 8.5; RRID:SCR_014325) software (National Instruments). The $x$ and $y$ positions of the target dot and the subjects' cursor were sampled at $100 \mathrm{~Hz}$. Off-line analysis was performed using Matlab (R2014b; RRID:SCR_001622) and Microsoft Excel 2013. Performance accuracy was measured by calculating the error rate based on the average track deviation (ATrD). That is, for each trial, the track deviation was measured as the Euclidian distance between the blue target line and the cursor position at each point in time, and then the track deviations within the trial were averaged. Better performance is thus reflected by lower values of $\mathrm{ATrD}$. For the acquisition phase analyses, data were averaged across every set of three data points in time, which resulted in 12 acquisition phase data points (TR1, TR2, .., TR12). Since different coordination directions (CW and CCW) were used only to provide an extra dimension of complexity to the task (as participants needed to alternate between them), CW and CCW data were collapsed. For the sake of simplification, we also chose to collapse the data from different frequency ratios. This decision was based on a control analysis performed with a $[2 \times 2 \times 12 \times 3(\mathrm{CI}$ (blocked, random $)) \times$ Age (young, old $) \times$ Time $(\mathrm{TR} 1-12) \times$ Frequency ratio $(1: 1,2: 3$ and 1:2)] repeated-measure ANOVA with CI and Age as between-subject factors and Time and Frequency ratio as within-subject factors. This analysis revealed a significant main effect of Frequency ratio $\left(F_{(2,112)}=136, p<0.001\right)$. Post hoc (Tukey's) analysis revealed that the $1: 1$ frequency ratio was easier to perform than the 2:3 and 1:2 frequency ratios, whereas performance during the latter two did not significantly differ from each other $(p>$ 0.05). This is in line with previous studies in our group (Sisti et al., 2011; Pauwels et al., 2014, 2015). A significant Frequency ratio $X$ Time interaction $\left(F_{(22,1232)}=1.833, p=0.01\right)$ indicated that over time, performance evolved differently across Frequency ratios. More specifically, performance improved to a greater extent in the 2:3 and 1:2 frequency ratios compared with the $1: 1$ frequency ratio, especially at the beginning of practice. Importantly, the effects of Age and CI did not interact with Frequency ratio, as there were no significant Frequency ratio $\times$ Time $\times$ CI effect $\left(F_{(22,1232)}=\right.$ $0.845, p=0.67)$, Frequency ratio $\times$ Time $\times$ Age effect $\left(F_{(22,1232)}=1.093, p=0.347\right)$, or Frequency ratio $\times$ Time $\times$ CI $\times$ Age effect $\left(F_{(22,1232)}=0.793, p=0.737\right)$ interaction effects. As none of the between-subject factors of interest (i.e., CI and Age) significantly interacted with Frequency ratio $X$ Time, we elected to collapse data across Frequency ratios for subsequent analyses.

To assess how performance evolves in each practice group when no visual guidance was provided, i.e., when participants produce movements primarily based on the internal representation of the movement patterns instead of having the opportunity to make on-line corrections based on external visual information, only trials without concurrent visual feedback were used for the behavioral analyses of the acquisition phase data (216 trials in total). Baseline and retention tests consisted of only NFB trials; hence the ATrD from all the move trials within baseline, DR-B, and DR-R were averaged to have one data point for each block.

In addition to the absolute error measurement (ATrD), we also examined the amount of skill loss between acquisition and delayed retention for each participant. Therefore, a forgetting score was calculated for each participant and was defined as the difference between the performance error of DR and the end of acquisition (TR12). To reduce the positive skew that was present in our data, data were log-transformed (base 10 logarithm).

Statistical analysis. Statistical analyses were conducted using Statistica (version 13.1; RRID:SCR_014213). For all the analyses, the critical probability level was set at $p<0.05$, two-sided. When significant effects were found, post hoc analyses were conducted using Tukey's HSD.

To assess whether performance before practice differed across age and CI groups, baseline performance was analyzed using a $2 \times 2$ [Age (YA, $\mathrm{OA}) \times \mathrm{CI}$ (blocked, random)] factorial ANOVA. Acquisition phase data were analyzed using a $2 \times 2 \times 12$ [Age $(Y A, O A) \times C I$ (blocked, random) $\times$ Time (TR1-12)] repeated-measures ANOVA with Age and CI as between-subject factors and Time as the within-subject factor. To assess retention performance, a $2 \times 2 \times 2$ [Age (YA, OA) $\times$ CI (blocked, random) $\times$ Retention Order (DR-B, DR-R)] repeated-measures ANOVA was conducted with Age and CI as between-subject factors and Retention Order as the within-subject factor. Furthermore, we investigated whether individuals with greater rate of performance improvement during the acquisition phase had better retention performance and whether this was dependent on the CI practice group. Results of the latter analysis are reported in the supplemental material.

We aimed to test whether random practice, compared with blocked practice, leads to better skill persistence in both age groups (Pauwels et al., 2015). To do so, planned comparisons of least-square means were conducted on the full model $[2 \times 2 \times 15($ Age $\times$ CI $\times$ Time $)$ ANOVA] to test the hypothesized differential change in performance, i.e., difference in post-acquisition processes from the end of acquisition to delayed retention between the two CI conditions. Furthermore, a $2 \times 2$ [Age (YA, 
OA) $\times$ CI (blocked, random)] factorial ANOVA was conducted to test the influence of CI on skill forgetting from end of acquisition to DR in both age groups.

\section{Imaging analysis}

Imaging data were analyzed using the FMRIB Software Library (FSL 5.0; RRID:SCR_002823; Smith, 2004; Woolrich et al., 2009). First, the Brain Extraction Tool was used on the T1 and field map images to extract brain from the dura and skull. The fMRI data were preprocessed using FEAT (FMRI Expert Analysis Tool) from FMRIB's Software Library. MCFLIRT motion correction was used to realign EPIs to the middle volume of each run, and a high-pass filter with a cutoff of $200 \mathrm{~s}$ was used. Subsequently, B0 field map unwarping was performed to correct for geometric distortion. Slice timing correction was applied along with spatial smoothing using a full-width half-maximum of $5 \mathrm{~mm}$. EPIs were coregistered to the T1 image (Boundry-based registration) and subsequently to the MNI (Montreal Neurological Institute) template using FNIRT (12 DoF affine transformation). For a number of subjects ( $n=3$ per group), the nonlinear registration did not work adequately and was replaced by a linear transformation (FLIRT). One older participant was excluded from the analysis as neither FNIRT nor FLIRT led to a tolerable registration. Regressors of the conditions of interest (move FB, move NFB, no-move FB, and no-move NFB) and their first temporal derivatives were defined for the execution ( $9 \mathrm{~s}$ ) phase of each condition. Error scores of the participant were also included in the models as linear parametric modulators. ICA-based automatic removal of motion artifacts (ICA-AROMA) was used to remove motion-related ICA components from the fMRI data (Pruim et al., 2015). In addition, time series from the white matter and CSF masks were added as additional confound explanatory variables in FEAT to disregard volumes with motion artifacts.

After the first-level analysis, for each participant three second-level fixed-effect models were performed: the first fixed-effect model collapsed trials across the 12 runs of training to investigate the overall acquisition phase effect (DAY1-DAY3), the second fixed-effect model collapsed across 6 runs within each day of training to investigate Time effect (DAY1 and DAY3 separately), and the third fixed-effect model collapsed across 2 runs of DR as the effect of retention order (DR-B and DR-R) was not significant in the behavioral results (see Results for more detail). Examining neural recruitment patterns of different types of feedback were beyond the scope of this study. For each second-level fixedeffect model, linear contrasts testing for the main effect of movement (i.e., move vs no-move) regardless of $\mathrm{FB}$ conditions (there was an equal number of trials with $\mathrm{cFB}$ and atFB within each run) were written. At the group level, three models were designed. Modell investigated differences in the neural activation between blocked and random practice conditions (main effect of CI) during the overall acquisition phase (DAY1-DAY3) across the two age groups. As we hypothesized that the effect of Time from the early (DAY1) to late (DAY3) phase of learning would be different between CI conditions within each Age group, Model2 investigated the Time $\times$ CI effect in OA and YA, separately. Last, Model3 tested the effects of CI and the interaction with Age on DR data (DR-B and DR-R collapsed). Higher-level group analyses were conducted using the randomeffects model of FSL (FLAME1). A gray matter mask was created such that only gray matter voxels were included. All fMRI analyses were conducted using Gaussian Random Field Theory at the cluster level using $Z>2.3$ and a cluster probability threshold of $p<0.05$. The activation peak of each cluster will be reported together with local maxima if the cluster spans multiple regions. Labeling of areas was based on the "HarvardOxford cortical structural atlas" and "Harvard-Oxford subcortical structural atlas" (Frazier et al., 2005; Desikan et al., 2006; Makris et al., 2006; Goldstein et al., 2007) and the "Juelich histological atlas" (Eickhoff et al., 2005, 2006, 2007) in FSL. The "Cerebellar atlas in MNI152 space after normalization with FNIRT" was used for identifying cerebellar structures (Diedrichsen et al., 2009).

\section{Results}

\section{Behavioral results}

Results of the behavioral analyses are represented in Table 2 and Figure 5.
Table 2. Behavioral results

\begin{tabular}{|c|c|c|c|}
\hline & $\mathrm{df}_{1}, \mathrm{df}_{2}$ & $F$ & $p$ \\
\hline \multicolumn{4}{|l|}{ Baseline } \\
\hline Age & 1,56 & 9.382 & $0.003^{* *}$ \\
\hline $\mathrm{Cl}$ & 1,56 & 0.001 & 1 \\
\hline Age $\times \mathrm{Cl}$ & 1,56 & 0.001 & 0.972 \\
\hline \multicolumn{4}{|l|}{ Acquisition phase } \\
\hline Age & 1,56 & 36.148 & $<0.001^{* * *}$ \\
\hline $\mathrm{Cl}$ & 1,56 & 14.823 & $<0.001^{* * *}$ \\
\hline Age $\times \mathrm{Cl}$ & 1,56 & 0.807 & 0.373 \\
\hline Time & 11,616 & 52.475 & $<0.001^{* * *}$ \\
\hline Time $\times$ Age & 11,616 & 3.416 & $<0.001^{* * *}$ \\
\hline Time $\times \mathrm{Cl}$ & 11,616 & 1.782 & 0.054 \\
\hline Time $\times$ Age $\times \mathrm{Cl}$ & 11,616 & 0.597 & 0.832 \\
\hline \multicolumn{4}{|l|}{ Delayed retention } \\
\hline Age & 1,52 & 9.540 & $0.003^{* *}$ \\
\hline $\mathrm{Cl}$ & 1,52 & 12.003 & $0.001^{* *}$ \\
\hline Age $\times \mathrm{Cl}$ & 1,52 & 0.217 & 0.463 \\
\hline Retention Order & 1,52 & 0.105 & 0.747 \\
\hline Retention Order $\times$ Age & 1,52 & 0.327 & 0.570 \\
\hline Retention Order $\times \mathrm{Cl}$ & 1,52 & 2.652 & 0.109 \\
\hline Retention Order $\times$ Age $\times \mathrm{Cl}$ & 1,52 & 0.165 & 0.686 \\
\hline \multicolumn{4}{|l|}{ Skill forgetting } \\
\hline Age & 1,56 & 0.748 & 0.390 \\
\hline $\mathrm{Cl}$ & 1,56 & 41.747 & $<0.001^{* * *}$ \\
\hline Age $\times \mathrm{Cl}$ & 1,56 & 0.697 & 0.407 \\
\hline
\end{tabular}

${ }^{* *} p<0.01 ; * * * p<0.001$.

With respect to baseline performance, the $2 \times 2($ Age $\times \mathrm{CI})$ ANOVA revealed a main effect of Age, indicating that before practice, YA performed the task better than OA. There was no significant main effect of CI, indicating that there was no difference in the baseline performance between CI practice conditions. This was the case for both age groups, as there was no significant Age $\times$ CI interaction effect.

Regarding the acquisition phase, a main effect of Time was observed, indicating an overall improvement of performance over the course of training in both age groups. We found that OA showed lower performance compared with YA, reflected by a main effect of Age. Moreover, a Time $\times$ Age interaction effect was observed indicating that performance of YA improved to a larger extent compared with OA, with larger performance differences at the end $(p<0.001)$ compared with the beginning $(p>$ $0.05)$ of practice. Nevertheless, the post hoc test indicated that both age groups significantly improved their performance from TR1 to TR12 ( $p<0.001$ for both YA and OA). Furthermore, a main effect of CI was observed showing that the overall performance level during the acquisition phase was better when following blocked compared with random practice. This was the case in both age groups, as the interaction effect of Age $\times$ CI was not significant. Furthermore, we found a trend toward significance for the Time $\times$ CI interaction effect, indicating that performance in the blocked group was better at the beginning of acquisition (TR1, $p<0.05$ ), but this performance benefit became less pronounced at the end of acquisition (TR12, $p>0.05$ ) as the random condition showed more improvement over the course of training. This effect was observed in both age groups, as no significant interaction effect of Time $\times \mathrm{CI} \times$ Age was observed.

Analysis of retention data showed a main effect of $\mathrm{CI}$ indicating better retention performance following random relative to blocked practice. This holds for both age groups, as no significant interaction effect of Age $\times$ CI was found. However, a main effect of Age was observed, indicating that OA had more difficulty performing the task compared with YA, reflected by higher error 


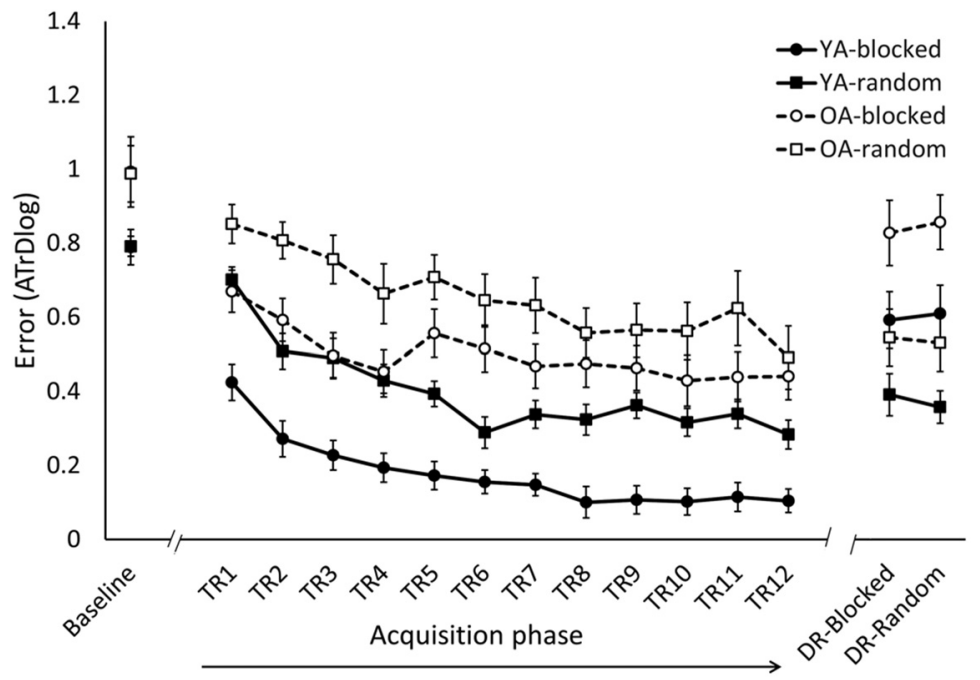

Figure 5. Behavioral results. The error score (ATrD, i.e., the log-transformed average track deviation) for baseline, acquisition phase (TR1-TR12), and DR (mean $\pm \mathrm{SE}$ ) is shown. Within each age group, i.e., young (YA, solid line) and older (OA, dashed line) adults, the bimanual task was practiced following either a blocked (circles) or random (squares) schedule. Better performance is reflected by lower levels of ATrD. Performance of $O A$ was significantly lower compared with performance of $Y A$ during baseline $(p<0.01)$, acquisition phase $(p<0.001)$, and DR $(p<0.01)$, reflected by higher levels of ATrD. In both age groups, random practice was detrimental during the acquisition phase $(p<0.001)$ but resulted in better retention performance $(p<0.01)$ compared with blocked practice.

Table 3. Model1: Main effect of $\mathrm{Cl}$ during the acquisition phase

\begin{tabular}{lrrrrr}
\hline Brain region & $\begin{array}{l}\text { Peak activation } \\
\text { coordinates }(x, y, z)\end{array}$ & Z value & $p$ value \\
\hline Blocked > random & & & & & \\
$\quad$ R M1, also R S1 & 16 & -30 & 66 & 5.43 & $<0.001$ \\
L SMA; also L M1, L S1, and L PMd & -10 & -18 & 66 & 5.56 & $<0.001$ \\
L/R CER lobes I-IV & 0 & -48 & -4 & 3.92 & 0.005 \\
R anterior MTG, also R temporal pole & 50 & 2 & -28 & 4.51 & 0.007 \\
$\quad$ and R amygdala & & & & & \\
R CER CR1, also R CER lobe VIIb and & 46 & -54 & -30 & 4.79 & 0.022 \\
$\quad$ R CER lobe VI & & & & & \\
Random > blocked & & & & & \\
R hMT/V5+, also R temporo-occipital & 58 & -64 & -12 & 5.45 & $<0.001$ \\
$\quad$ and posterior MTG & & & & & \\
L superior LOC & -32 & -74 & 32 & 5.42 & $<0.001$ \\
R posterior precuneus, also R superior L0C & 10 & -76 & 48 & 4.15 & $<0.001$ \\
R medial frontal/paracingulate gyrus, & 10 & 24 & 44 & 5.26 & $<0.001$ \\
$\quad$ also R SFG & & & & & \\
L temporo-occipital ITG & -64 & -48 & -16 & 4.04 & 0.006 \\
R PCC, also R ACC & 8 & -24 & 28 & 4.48 & 0.011 \\
\hline
\end{tabular}

Shown are locations of main cluster activation peaks (MNI coordinates) and $Z$ scores for brain regions showing a main effect of CI ( $Z>2.3$; cluster significance: $p<0.05$, corrected). R, Right; L, left; PMd, dorsal premotor cortex; CER, cerebellum; CR1, crus 1; ACC, anterior cingulate cortex.

scores during retention. To ensure that acquisition-retention compatibility was similar for the two CI conditions, retention was acquired following a blocked (DR-blocked) and a random (DRrandom) retention order. However, retention performance was not influenced by the order in which retention was obtained, as there was neither a significant main effect of Retention Order nor significant interaction effects of Retention Order $\times$ Age, Retention Order $\times$ CI, or Retention Order $\times$ Age $\times$ CI.

Planned comparisons revealed a significant difference between random and blocked practice from the end of acquisition (TR12) to DR in both young and older adults $(p<0.001$ for both YA and OA). In other words, participants who followed random practice during the acquisition phase retained their skill to a higher degree compared with participants who followed a blocked practice. Moreover, the $2 \times 2$ $(\mathrm{CI} \times$ Age $)$ ANOVA on forgetting scores revealed that following random practice, OA were similarly able to retain their skill compared to YA.

\section{Imaging results \\ Model1: Main effect of CI during the acquisition phase}

The first model (Model1) assessed differences in the neural activation during move trials (compared with no-move trials) between blocked and random practice conditions during the overall acquisition phase (averaged across the first and last days of practice and both age groups). Brain regions showing significant activation in each contrast are listed in Table 3. Compared with random practice, blocked practice induced more activation in the sensorimotor areas [bilateral M1, bilateral primary somatosensory cortex (S1), left supplementary motor area (SMA), and left dorsal PM], cerebellar areas (bilateral lobe I-IV and right crus I), and right middle temporal gyrus (MTG), including right temporal pole. In contrast, random practice, compared with blocked practice, highly recruited the regions important in visual processing, such as right human middle temporal complex (hMT/V5+), bilateral lateral occipital cortex (LOC), right posterior precuneus and left inferior temporal gyrus (ITG), as well as paralimbic cortical structures such as right paracingulate gyrus and right posterior cingulate cortex (PCC).

\section{Model2: Time $\times$ CI within $Y A$ and $O A$ during the acquisition phase}

Model 2 assessed whether brain activity was differently modulated from early (DAY1) to late (DAY3) phases of learning between different $\mathrm{CI}$ groups (Time $\times \mathrm{CI}$ interaction). Clusters showing a significant interaction effect of Time $\times \mathrm{CI}$ in YA and OA are listed in Tables 4 and 5, respectively.

In YA, a significant Time $\times$ CI interaction effect was observed in a set of regions including frontal, parietal, temporal, motor, and cerebellar areas. Inspection of the time effect within each CI group revealed decreased activity in the typical motor-related areas (bilateral SMA, bilateral M1, and bilateral S1 and various cerebellar subregions such as right vermis VIIIa; for extending regions, see Table 4) throughout the process (i.e., from DAY1 to DAY3) of blocked practice, whereas activity in these regions was stable over time during random practice (Fig. 6A). The same pattern of activity was found for the bilateral superior frontal gyrus and left parietal operculum. That is, a decrease in activity after blocked practice, whereas during random practice, activity in these regions did not change. The only region that showed higher activity in random practice on DAY3 compared with DAY1 was right temporal gyrus (ITG: for extending regions, see Table 4). This is because activity in this region did not change over the course of blocked practice.

In OA, a significant Time $\times$ CI interaction effect was observed in a set of regions including motor, cerebellar, temporal, and subcortical regions as well as regions associated with the default mode network (DMN). Inspection of the effect revealed a similar pattern as in YA, in which the blocked groups relied more on the 
Table 4. Model2: Time $\times$ Cl within YA during the acquisition phase

\begin{tabular}{|c|c|c|c|c|c|}
\hline \multirow{2}{*}{$\begin{array}{l}\text { Brain region } \\
\text { YA-blocked (DAY1 >DAY3) > YA-random (DAY1 >DAY3) }\end{array}$} & \multicolumn{3}{|c|}{ Peak activation coordinates $(x, y, z)$} & \multirow[t]{2}{*}{ Zvalue } & \multirow[t]{2}{*}{$p$ value } \\
\hline & & & & & \\
\hline R CER vermis VIIIa; also L CER CR1, L CER lobes I-IV, R CER VIIb, and L CER lobe VI & 2 & -68 & -38 & 5.45 & $<0.001$ \\
\hline L/R SFG, also R paracingulate gyrus and L frontal pole & 0 & 50 & 46 & 4.55 & $<0.001$ \\
\hline LS1; also L M1 and L/R SMA & -20 & -38 & 74 & 6.27 & $<0.001$ \\
\hline LSMA; also R SMA, R ACC, LPCC, and L precuneus & -4 & -16 & 52 & 4.89 & 0.002 \\
\hline L parietal operculum cortex, also L supramarginal gyrus and L planum temporale & -54 & -26 & 18 & 4.73 & 0.004 \\
\hline RS1, also RM1 & 26 & -36 & 70 & 5.36 & 0.015 \\
\hline R anterior ITG; also $R$ anterior MTG, $R$ planum polare, $R$ temporal pole, and $R$ insula & 46 & -2 & -36 & 3.91 & 0.033 \\
\hline \multicolumn{6}{|l|}{ YA-random (DAY1 > DAY3) > YA-blocked (DAY1 > DAY3) } \\
\hline
\end{tabular}

Shown are locations of main cluster activation peaks (MNI coordinates) and $Z$ scores for brain regions showing a significant Time $\times$ Cl interaction effect from DAY1 to DAY3 acquisition phase in YA ( $Z>2.3$; cluster significance: $p<0.05$, corrected). R, Right; L, left; CER, cerebellum; CR1, crus 1; SFG, superior frontal gyrus; ACC, anterior cingulate cortex.

Table 5. Model2: Time $\times \mathrm{Cl}$ within $0 \mathrm{~A}$ during the acquisition phase

\begin{tabular}{|c|c|c|c|c|c|}
\hline \multirow{2}{*}{$\frac{\text { Brain region }}{\text { OA-blocked (DAY1 }>\text { DAY3) }>\text { OA-random (DAY1 > DAY3) }}$} & \multicolumn{3}{|c|}{$\begin{array}{l}\text { Peak activation } \\
\text { coordinates }(x, y, z)\end{array}$} & \multirow[t]{2}{*}{$Z$ value } & \multirow[t]{2}{*}{$p$ value } \\
\hline & & & & & \\
\hline RSMA, also RS1 and R M1 & 10 & -12 & 58 & 5.79 & $<0.001$ \\
\hline LS1, also L M1 & -52 & -30 & 60 & 5.58 & $<0.001$ \\
\hline L PMv; also L central opercular cortex, L posterior STG, L temporo-occipital MTG, and inferior LOC & -62 & 0 & 30 & 5.15 & $<0.001$ \\
\hline R CER lobe V, also R CER lobes I-IV & 18 & -42 & -16 & 4.51 & 0.001 \\
\hline \multicolumn{6}{|l|}{ OA-random (DAY1 >DAY3) > 0A-blocked (DAY1 >DAY3) } \\
\hline $\mathrm{L}$ ventral precuneus; also L/R angular gyrus, L hippocampus, and L PCC & -4 & -38 & 50 & 5.95 & $<0.001$ \\
\hline LSFG, also L frontal pole and L IFG & -26 & 30 & 52 & 4.64 & $<0.001$ \\
\hline L/R medial PFC, also L SFG & 0 & 52 & 20 & 5.18 & $<0.001$ \\
\hline R CER CRII, also R occipital fusiform gyrus & 24 & -78 & -40 & 4.54 & $<0.001$ \\
\hline L anterior MTG; also posterior temporal fusiform cortex, $L$ frontal orbital cortex, $L$ temporal pole, $L$ amygdala, and $L$ hippocampus & -46 & 0 & -28 & 4.53 & $<0.001$ \\
\hline
\end{tabular}

Shown are locations of main cluster activation peaks (MNI coordinates) and $Z$ scores for brain regions showing a significant Time $\times$ Cl interaction effect from DAY1 to DAY3 acquisition phase in $0 A$ ( $Z>2.3$; cluster significance: $p<0.05$, corrected). R, Right; L, left; (ER, cerebellum; PMv, ventral premotor cortex; STG, superior temporal gyrus; SFG, superior frontal gyrus; IFG, inferior frontal gyrus; V1, primary visual area; V2, secondary visual area.

A

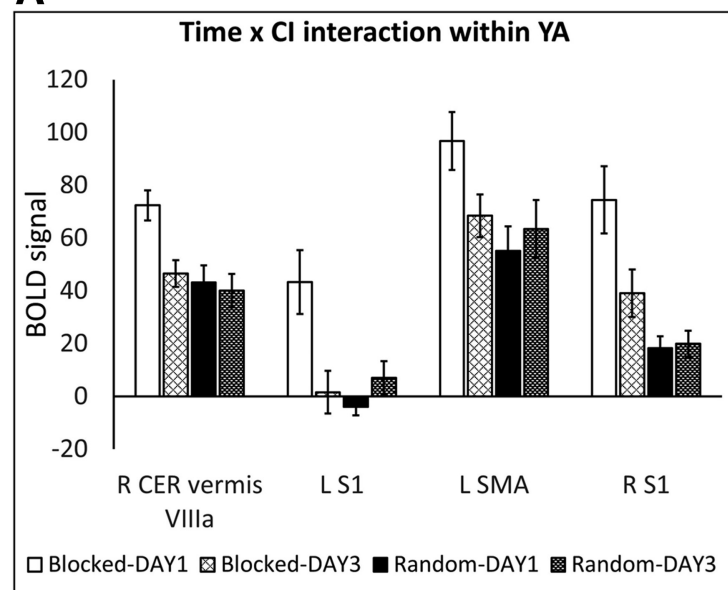

B

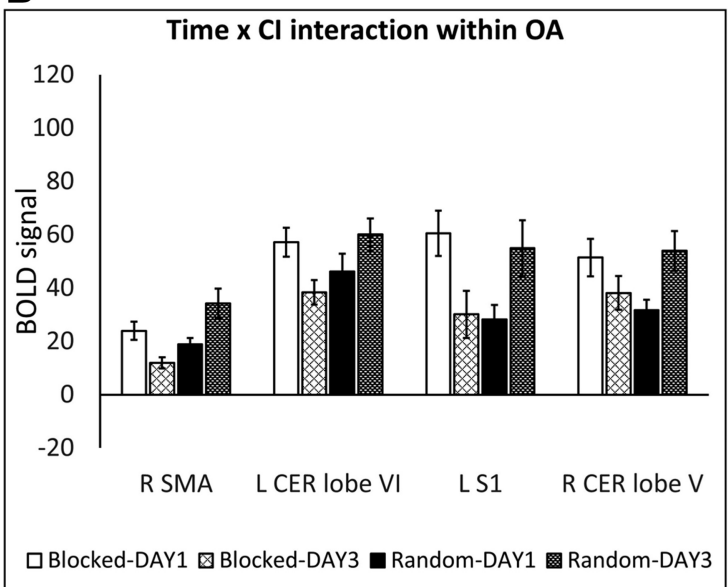

Figure 6. BOLD signal extracted from brain regions showing a significant Time $\times$ Cl interaction effect (Model2) in YA (A) and OA (B) adults. Throughout practice (DAY1 to DAY3), activity in motor and cerebellar regions decreased as a function of blocked practice, whereas after random practice, activity in these regions was either preserved (in $\mathrm{YA}$ ) or increased (in $0 \mathrm{~A}$ ). Clusterwise threshold $Z>2.3 ; p<0.05$. Error bars represent SE. CER, Cerebellum

sensorimotor (right SMA, bilateral S1, and bilateral M1) and cerebellar (left lobe VI and right lobe Vl; for extending regions, see Table 5) regions during the first day compared with the last day of practice. On the contrary, OA who followed a random practice schedule showed an increased dependence on these regions throughout the process of practice (Fig. 6B). A similar pattern of activation was found in left ventral PM and right insula (for extending regions, see Table 5), i.e., a decrease in activity was 

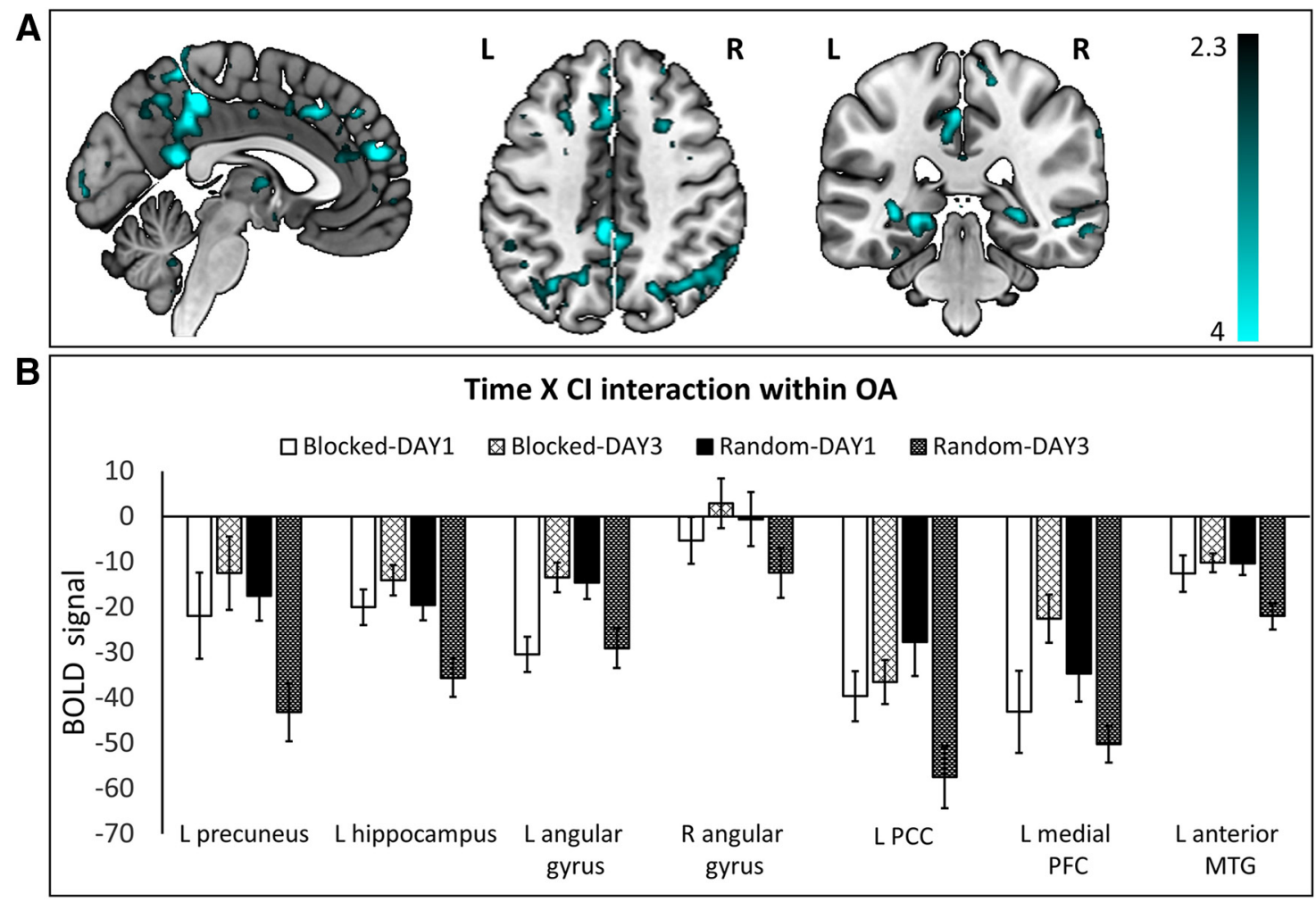

Figure 7. DMN regions showing a significant Time $\times$ Cl interaction effect (Model2) in 0A adults. A, Activation maps of the Time $\times$ Cl interaction in 0A were overlaid on a mni152 template using MRIcroGL. The color map depicts $Z$ values. $B, B O L D$ signal (mean \pm SE) extracted from voxels associated with DMN showing a significant Time $\times$ Cl interaction effect. Clusterwise threshold $Z>2.3$; $p<0.05$.

found throughout the process of blocked practice whereas the opposite effect, i.e., increase in activity, was observed over the course of random practice. Also, increased activity from the first to the last day of practice was observed in the left anterior superior temporal gyrus in random compared with blocked practice. Conversely, activity in the right pallidum (also including right putamen) and left caudate (also including bilateral thalamus) increased when practice progressed following blocked practice, whereas this was not the case following random practice.

Interestingly, OA showed a general pattern of results whereby activity in regions typically associated with the DMN was modulated differently through the course of the different $\mathrm{CI}$ practice schedules (Table 5; Fig. $7 A, B$ ). More specifically, activity in the left precuneus, bilateral angular gyrus, bilateral hippocampus, left PCC, bilateral medial, and bilateral lateral temporal cortex (mainly MTG and temporal pole) showed a decrease throughout the process of random practice whereas the opposite effect, i.e., increase in activity from DAY1 to DAY3, was found following blocked practice. This appears to suggest an increasing deactivation of areas of the default mode network as a result of the more challenging random practice condition.

\section{Model3: Main effect of $C I$ and interaction effect of $C I \times A g e$ during $D R$}

Model 3 assessed the effects of $\mathrm{CI}$ as well as its interaction with Age on brain activity during DR. Brain regions showing significant activation in each contrast are listed in Table 6.

During DR, blocked practice groups relied more on motorrelated areas, such as left SMA and bilateral M1, and subcortical areas, i.e., caudate nucleus and putamen, compared with random practice groups. By contrast, visual processing regions, such as right LOC, bilateral posterior precuneus, and right occipital cor-
Table 6. Model3: Cl effect during delayed retention

\begin{tabular}{|c|c|c|c|c|c|}
\hline \multirow{2}{*}{$\frac{\text { Brain region }}{\text { Blocked }>\text { random }}$} & \multicolumn{3}{|c|}{$\begin{array}{l}\text { Peak activation } \\
\text { coordinates }(x, y, z)\end{array}$} & \multirow[t]{2}{*}{$z$ value } & \multirow[t]{2}{*}{$p$ value } \\
\hline & & & & & \\
\hline L caudate, also L putamen & -16 & 18 & 10 & 4.28 & 0.024 \\
\hline LSMA, also L/R M1 & -8 & -18 & 68 & 3.59 & 0.037 \\
\hline \multicolumn{6}{|l|}{ Random $>$ blocked } \\
\hline $\begin{array}{l}\text { R superior } \mathrm{LOC} \text {, also } \mathrm{L} / \mathrm{R} \text { posterior } \\
\text { precuneus and R occipital cortex V1/V2 }\end{array}$ & 26 & -84 & 14 & 4.14 & $<0.001$ \\
\hline $\begin{array}{c}\text { Age } \times \text { CI }[0 \mathrm{~A}(\text { blocked }>\text { random })> \\
Y \mathrm{~A}(\text { blocked }>\text { random })]\end{array}$ & & & & & \\
\hline $\begin{array}{l}\text { L posterior cingulate, also L central } \\
\text { precuneus }\end{array}$ & -18 & -30 & 38 & 3.98 & 0.002 \\
\hline
\end{tabular}

Shown are locations of main cluster activation peaks (MNI coordinates) and $Z$ scores for areas showing a main effect of Cl and Age $\times$ Cl interaction effect ( $Z>2.3$; cluster significance: $p<0.05$, corrected). R, Right; L, left; V1, primary visual area; $\mathrm{V} 2$, secondary visual area.

tex V1/V2 were more active following random compared with blocked practice. Interestingly, a significant Age $\times \mathrm{CI}$ interaction effect was observed in the left PCC (considered to be part of the default mode resting-state network; Fig. 8A). Inspection of this effect revealed lower brain activation in OA following random compared with blocked practice, whereas the activity in this region did not differ between blocked and random groups in YA. In fact, further exploratory analysis (Pearson's correlation) in OA showed that activity in PCC was positively correlated with DR error score $(r=0.61, p<0.01)$ across the two practice schedules, indicating that lower PCC activation was associated with lower error (better performance) on DR, regardless of the practice schedule that the participant was trained under (Fig. 8B). 
A

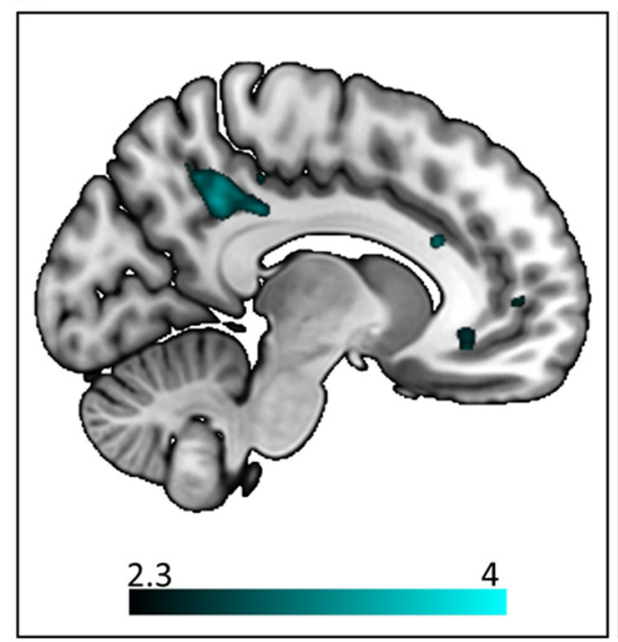

B

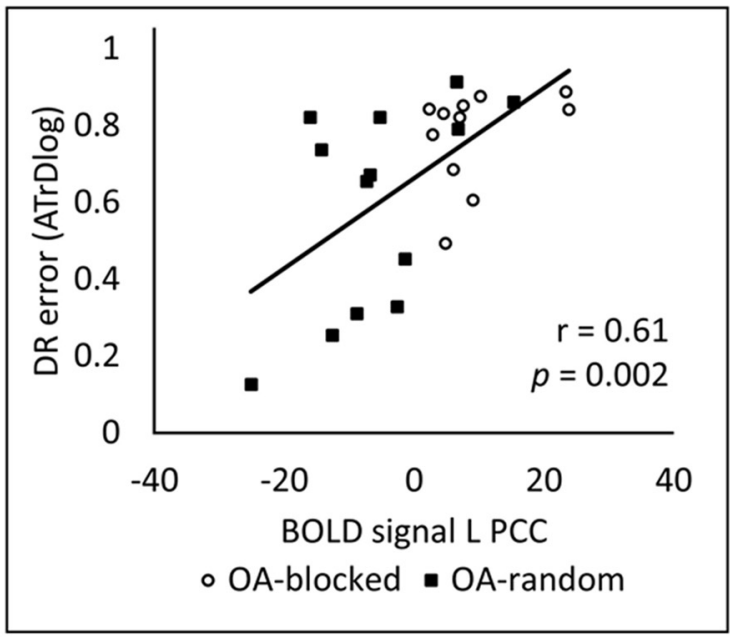

Figure 8. Activation map showing a significant Age $\times(\mathrm{Cl}$ interaction effect (Model3) in the left PCC during DR $(\boldsymbol{A})$ and Pearson's correlation between BOLD signal and DR error (B). $\boldsymbol{A}$, Activation map of the Age $\times$ Cl interaction during DR was overlaid on a mni152 template using MRIcroGL with a color map indicating Zvalues in activity maps. $\boldsymbol{B}$, Scatter plot correlation between BOLD signal extracted from the peak voxel (left PCC) and DR performance error. Older adults who followed blocked practice showed higher PCC activation compared with those who followed random practice, and this was positively correlated with error score during DR, indicating that greater $\mathrm{PCC}$ activation was associated with higher error (poorer performance) on DR. Activity in this region did not differ between the blocked and random groups within young adults. The Age $\times$ Cl interaction effect revealed significant activity in the $\mathrm{PCC}$, using a clusterwise threshold $Z>2.3$ and $p<0.05$.

\section{Discussion}

We examined the neural correlates of the CI effect while learning a bimanual coordination task in young and older adults. At the behavioral level, the typical CI effects were confirmed in both age groups. More specifically, random compared with blocked practice was more challenging during the acquisition phase, resulting in inferior levels of performance but leading to better subsequent retention (Shea and Morgan, 1979). Furthermore, the beneficial effects of random practice were preserved at older age (Lin et al., 2012; Pauwels et al., 2015). At the neural level, we demonstrated differences in task-related brain activations associated with different types of practice context beyond the traditionally used key-press-based sequential learning tasks. In both age groups, blocked compared with random practice activated motor-related brain regions, and recruitment of these regions decreased as a function of practice. Blocked practice also resulted in greater reliance on the SMA and striatum during skill retrieval. In contrast, the richer context of random practice required enhanced processing of visual information during both skill acquisition and retrieval, underscoring the task-dependent nature of the beneficial CI effects. Importantly, to the best of our knowledge, we provided the first evidence that DMN activity was modulated differently as a function of different practice schedules in older adults. We hypothesize that the extra challenge provided by the random practice schedule triggered age-related neuroplastic functional changes in the DMN, resulting in increased segregation of the task-related and DMN activations, ultimately leading to better retention performance.

Our findings indicated higher activation in motor-related brain regions following blocked practice and in visual (motion) processing regions following random practice. At first sight, these findings might seem to be in contrast with previous reports of greater involvement of sensorimotor (mainly M1), premotor (PM and SMA), prefrontal (DLPFC), and parietal (PPC) regions during skill acquisition under a random versus a blocked practice regime (for review, see Lage et al., 2015; Wright et al., 2016). However, as mentioned previously in the Introduction, the previous neuroscientific studies investigating the CI effect com- monly used sequential task learning (Cross et al., 2007; Lin et al., 2008, 2011; Wymbs and Grafton, 2009; Tanaka et al., 2010) and frontal-parietal networks (including PM, SMA, DLPFC, and PPC) are typically involved in sequence learning (Ziemann et al., 1995; Doyon et al., 2003).

In this study, we used a bimanual visuomotor task in which both the stimulus presentation (a moving target dot and the slope of the target line) and the feedback contained visual information important for task execution. In line with our hypothesis, our findings indicated higher recruitment of the right middle temporal area (hMT/V5+) during the acquisition of random versus blocked practice across age groups. This region plays a crucial role in visual motion processing (more specifically, the direction and speed of moving stimuli; Born and Bradley, 2005; Galletti and Fattori, 2018), as well as in extracting the relevant spatiotemporal features of feedback-guided movements during the execution of bimanual tasks and mapping these onto somatosensory information (Debaere et al., 2003; Woolley et al., 2010; Ronsse et al., 2011; Beets et al., 2015). In addition, LOC and ITG, which are mainly involved in the integration of different features of visual stimuli (Baars and Gage, 2010), and posterior precuneus, which is highly associated with perception, interpretation of visuospatial information, and guidance of actions (Margulies et al., 2009; Zhang and $\mathrm{Li}, 2012$ ), were also more active during random compared with blocked practice. Interestingly, LOC, precuneus, and V1 remained more active following random versus blocked practice during delayed retention, where augmented visual feedback was no longer provided. This implies that activity in these visual processing regions became an intrinsic part of the motor representation.

In contrast with random practice, blocked practice induced more activity in typical sensorimotor-related brain regions (i.e., M1, S1, SMA, and multiple cerebellar sub-areas) during the acquisition phase. This finding is inconsistent with previous reports of higher M1 activity following random versus blocked practice in sequence learning experiments by Wymbs and Grafton (2009) and Lin et al. (2011). It is noteworthy that Wymbs and Grafton (2009) captured this effect during movement execution of the final two-thirds of training data and Lin et al. (2011) did not 
distinguish between different phases of learning and collapsed the data from the two training days. However, we found that involvement of sensorimotor-related brain regions was mainly pronounced at the beginning of blocked practice training and then decreased with practice. Conversely, activity in these regions during random practice was either preserved (in young adults) or increased (in older adults) as practice progressed. Nevertheless, a decrease of sensorimotor processing with training has been previously observed in sequence (Dayan and Cohen, 2011) as well as bimanual task learning (Beets et al., 2015), suggesting more efficient task processing (Poldrack, 2000). Moreover, practicing sequential movements has been associated with decreased cerebellar activity (Doyon et al., 2003, 2009). Hence, our findings suggest that when task variants are presented in a repetitive (blocked) manner, they can be executed using fewer neuronal recourses as practice proceeds. However, this is not the case when the context of practice is constantly changing, confirming the resource demanding nature of random practice.

Blocked practice resulted in greater reliance on the left SMA and striatum (caudate and putamen). Higher involvement of the SMA during both acquisition and retention is not surprising, given its importance in internal movement generation (Debaere et al., 2003; Heuninckx et al., 2010). Involvement of this region following blocked practice is also in line with the observation that disruption of the SMA (by using repetitive Transcranial magnetic stimulation) immediately after practice resulted in deleterious effects on retention performance in the blocked but not in the random practice group (Tanaka et al. (2010). The striatum has also been associated with internal generation of movements (Debaere et al., 2003). Moreover, when asymptotic performance is achieved, and thus the skill has become automatic, activity in the corticostriatal system needs to be maintained to successfully retrieve the acquired motor skill (Doyon et al., 2009). Together, our findings suggest that skill retrieval in the blocked practice group relies on regions important in internal generation of motor commands whereas skill retrieval in the random practice group appears more externally generated, recruiting a system that is more flexible and highly attentive to the integration of visuospatial information and the required motor response.

Altogether, we hypothesize that in the blocked practice group, the decrease in activity in motor-related regions occurred in parallel to movement automatization. Despite the fact that participants in the blocked practice group presented very typical neural signatures of learning, the comparison with the random group indicated that their retention performance was poorer. These findings might indicate that participants following blocked practice repeated the task without paying much attention to the unique visual features of each subtask (e.g., inclination of the target line) and how these differed from each other (performed on different days). In fact, during delayed retention, the blocked group showed greater activity in the striatum, which is reflective of movement automaticity, i.e., they retrieved what they "perceived" as being successful skill execution. Although becoming automatic helped the blocked group temporarily during the acquisition phase, it limited their ability to clearly distinguish the representations of the different subtasks, reducing long-term benefits. On the contrary, frequently switching task sets during random practice required more attention to be deployed to the external (visual) features of the task for a detailed processing of the stimulus structure as well as movement-generated visual feedback. Hence, by providing a richer practice context, the learner became highly attentive to the visual features of the task to successfully integrate this information with somatosensory processing and to couple this with the appropri- ate motor program for each subtask. Our findings suggest a modality-specific effect of CI that may be associated with the strong visual features of this bimanual visuomotor task. In other words, when the underlying basis of the CI effect would be studied in a different motor task where the visual component is less pronounced, one might expect a greater contribution of other brain regions. The present findings may have clinical relevance for disordered groups who show degradation of brain regions involved in automaticity or internal generation of movements (such as in Parkinson's disease). Hence, a random practice context might provoke higher involvement of externally driven movements, thereby bypassing the network encompassing the impaired brain regions (such as striatum and SMA). However, future work is needed to test this hypothesis.

With regard to the previously discussed behaviorally based theoretical accounts of the CI effect, i.e., the elaboration and action-plan reconstruction hypotheses, the following is noteworthy: even though our imaging findings do not provide unequivocal evidence for one of both hypotheses, they seem to favor the elaboration hypothesis (Shea and Morgan, 1979; Shea and Zimny, 1983). More specifically, the higher involvement of visual processing regions during random compared with blocked practice suggests more elaborate (intertask) processing of the visuospatial features of the different task variants, resulting in a more distinctive memory representation of the subtasks. Although this supports the elaboration hypothesis, the more widespread brain activation pattern in the random group compared with the blocked practice group may also be consistent with the action-plan reconstruction hypothesis that is more neural resource demanding. As such, these hypotheses are not mutually exclusive.

Our most interesting finding is that in older adults, brain activity in regions typically associated with the DMN (i.e., bilateral medial PFC, left PCC, bilateral angular gyrus, bilateral hippocampus, and bilateral lateral temporal cortex) were differently modulated throughout the course of different CI practice schedules. That is, with practice, activity in the DMN regions increased in the blocked group and decreased in the random group. Previous studies have shown that the DMN is more active during periods of task-unrelated self-generated or stimulus-independent thoughts (Buckner et al., 2008; Allen et al., 2013; Smallwood and Schooler, 2015), which occur not only during rest but also when performing an external task (Antrobus et al., 1970; Buckner et al., 2008). However, the occurrence of stimulus-independent thoughts is reduced when a task becomes more demanding (McKiernan et al., 2003, 2006). Mason et al. (2007) demonstrated that when performing a practiced (low-demand) compared with a novel (high-demand) task variant, more stimulus-independent thoughts occurred in the former condition, and this was associated with activity in DMN regions, such as medial PFC and PCC. Extending these results to our findings, it appears that increasing task engagement by providing a more demanding random practice schedule led to a decrease in DMN activity as practice progressed. Moreover, during skill retrieval (delayed retention), lower activity in the PCC was persistently observed in the random compared with the blocked group, and this was associated with better retention performance. This provides further support for the hypothesis that the training-induced ability to suppress this core region of the DMN is beneficial for skill retrieval.

These results are particularly interesting because the DMN shows increased vulnerability with aging (Lustig et al., 2003; Grady et al., 2006; Sambataro et al., 2010), usually demonstrated by (1) a decrease in resting-state functional connectivity within the DMN (Ferreira and Busatto, 2013) and/or (2) a decrease in deactivation 
in brain regions typically associated with the DMN during task execution (Lustig et al., 2003; Grady et al., 2006; Sambataro et al., 2010). In a study by Grady et al. (2006), it was demonstrated that aging leads to a reduction in task-relevant brain activity during the execution of memory tasks. Concomitantly, the authors observed an age-related increase in activity in brain regions associated with the DMN, more specifically, the PCC and medial PFC. These findings led to the idea that age-related modulation in the balance between activity in regions associated with the default mode network on the one hand and activity in task-relevant regions on the other hand could account for the increased susceptibility to distraction from irrelevant information with age (Grady et al., 2006). Please note that this observation refers to task execution. To the best of our knowledge, we provide the first evidence that activity in regions associated with DMN as well as task-relevant (motor-related) brain regions can be modulated as a function of learning and according to different CI practice schedules in older adults. This opens exciting perspectives for a training-induced modulation of DMN activity in older adults.

In conclusion, our findings indicate a differential modulation of brain regions as a function of practice schedule and suggest that the extra challenge provided by a random practice schedule paves the way for functional network plasticity with positive behavioral effects. These findings may have important implications for clinical practice.

\section{Notes}

Supplemental material for this article is available at https://figshare. com/articles/SupplementaryMaterial_Pauwels_J_Neurosci_docx/ 5663233. Results of a regression analysis (Table S1) indicated that better individual learners within both CI practice groups, and particularly within the random practice group, had better longer-term retention (Figure S1), which again highlights the beneficial effects of random practice schedule. This material has not been peer reviewed.

\section{References}

Allen M, Smallwood J, Christensen J, Gramm D, Rasmussen B, Jensen CG, Roepstorff A, Lutz A (2013) The balanced mind: the variability of taskunrelated thoughts predicts error monitoring. Front Hum Neurosci 7:743. CrossRef Medline

Antrobus JS, Singer JL, Goldstein S, Fortgang M (1970) Mindwandering and cognitive structure. Trans N Y Acad Sci 32:242-252. CrossRef Medline

Baars JB, Gage MN (2010) Vision. In: Cognition, brain and consciousness (Baars JB, Gage MN, eds), pp 157-194. Burlington, MA, San Diego, CA, Oxford, UK: Academic Press, imprint of Elsevier.

Beets IA, Gooijers J, Boisgontier MP, Pauwels L, Coxon JP, Wittenberg G, Swinnen SP (2015) Reduced neural differentiation between feedback conditions after bimanual coordination training with and without augmented visual feedback. Cereb Cortex 25:1958-1969. Medline

Born RT, Bradley DC (2005) Structure and function of visual area MT. Annu Rev Neurosci 28:157-189. CrossRef Medline

Buckner RL, Andrews-Hanna JR, Schacter DL (2008) The brain's default network: anatomy, function, and relevance to disease. Ann N Y Acad Sci 1124:1-38. CrossRef Medline

Cross ES, Schmitt PJ, Grafton ST (2007) Neural substrates of contextual interference during motor learning support a model of active preparation. J Cogn Neurosci 19:1854-1871. CrossRef Medline

Dayan E, Cohen LG (2011) Neuroplasticity subserving motor skill learning. Neuron 72:443-454. CrossRef Medline

Debaere F, Wenderoth N, Sunaert S, Van Hecke P, Swinnen SP (2003) Internal vs external generation of movements: differential neural pathways involved in bimanual coordination performed in the presence or absence of augmented visual feedback. Neuroimage 19:764-776. CrossRef Medline

Desikan RS, Ségonne F, Fischl B, Quinn BT, Dickerson BC, Blacker D, Buckner RL, Dale AM, Maguire RP, Hyman BT, Albert MS, Killiany RJ (2006) An automated labeling system for subdividing the human cerebral cortex on mri scans into gyral based regions of interest. Neuroimage 31:968980. CrossRef Medline
Diedrichsen J, Balsters JH, Flavell J, Cussans E, Ramnani N (2009) A probabilistic MR atlas of the human cerebellum. Neuroimage 46:39-46. CrossRef Medline

Doyon J, Penhune V, Ungerleider LG (2003) Distinct contribution of the cortico-striatal and cortico-cerebellar systems to motor skill learning. Neuropsychologia 41:252-262. CrossRef Medline

Doyon J, Bellec P, Amsel R, Penhune V, Monchi O, Carrier J, Lehéricy S, Benali H (2009) Contributions of the basal ganglia and functionally related brain structures to motor learning. Behav Brain Res 199:61-75. CrossRef Medline

Eickhoff SB, Stephan KE, Mohlberg H, Grefkes C, Fink GR, Amunts K, Zilles K (2005) A new SPM toolbox for combining probabilistic cytoarchitectonic maps and functional imaging data. Neuroimage 25:1325-1335. CrossRef Medline

Eickhoff SB, Heim S, Zilles K, Amunts K (2006) Testing anatomically specified hypotheses in functional imaging using cytoarchitectonic maps. Neuroimage 32:570-582. CrossRef Medline

Eickhoff SB, Paus T, Caspers S, Grosbras MH, Evans AC, Zilles K, Amunts K (2007) Assignment of functional activations to probabilistic cytoarchitectonic areas revisited. Neuroimage 36:511-521. CrossRef Medline

Ferreira LK, Busatto GF (2013) Resting-state functional connectivity in normal brain aging. Neurosci Biobehav Rev 37:384-400. CrossRef Medline

Frazier JA, Chiu S, Breeze JL, Makris N, Lange N, Kennedy DN, Herbert MR, Bent EK, Koneru VK, Dieterich ME, Hodge SM, Rauch SL, Grant PE, Cohen BM, Seidman LJ, Caviness VS, Biederman J (2005) Structural brain magnetic resonance imaging of limbic and thalamic volumes in pediatric bipolar disorder. Am J Psychiatry 162:1256-1265. CrossRef Medline

Galletti C, Fattori P (2018) The dorsal visual stream revisited: Stable circuits or dynamic pathways? Cortex 98:203-217. CrossRef Medline

Goldstein JM, Seidman LJ, Makris N, Ahern T, O’Brien LM, Caviness VS Jr, Kennedy DN, Faraone SV, Tsuang MT (2007) Hypothalamic abnormalities in schizophrenia: sex effects and genetic vulnerability. Biol Psychiatry 61:935-945. CrossRef Medline

Grady CL, Springer MV, Hongwanishkul D, McIntosh AR, Winocur G (2006) Age-related changes in brain activity across the adult lifespan. J Cogn Neurosci 18:227-241. CrossRef Medline

Heuninckx S, Wenderoth N, Swinnen SP (2010) Age-related reduction in the differential pathways involved in internal and external movement generation. Neurobiol Aging 31:301-314. CrossRef Medline

Kovacs AJ, Shea CH (2011) The learning of 90 degrees continuous relative phase with and without lissajous feedback: external and internally generated bimanual coordination. Acta Psychol 136:311-320. CrossRef

Lage GM, Ugrinowitsch H, Apolinário-Souza T, Vieira MM, Albuquerque MR, Benda RN (2015) Repetition and variation in motor practice: a review of neural correlates. Neurosci Biobehav Rev 57:132-141. CrossRef Medline

Lee TD, Magill RA (1983) The locus of contextual interference in motorskill acquisition. J Exp Psychol Learn Mem Cogn 9:730-746. CrossRef

Lee TD, Magill RA (1985) Can forgetting facilitate skill acquisition? In: Differing perspectives in motor learning, memory, and control (Goodman D, Wilberg RB, Franks IM, eds), pp 3-22. Amsterdam: Elsevier.

Lin CH, Fisher BE, Winstein CJ, Wu AD, Gordon J (2008) Contextual interference effect: elaborative processing or forgetting-reconstruction? A post hoc analysis of transcranial magnetic stimulation-induced effects on motor learning. J Mot Behav 40:578-586. CrossRef Medline

Lin $\mathrm{CH}$, Knowlton BJ, Chiang MC, Iacoboni M, Udompholkul P, Wu AD (2011) Brain-behavior correlates of optimizing learning through interleaved practice. Neuroimage 56:1758-1772. CrossRef Medline

Lin $\mathrm{CH}$, Chiang MC, Wu AD, Iacoboni M, Udompholkul P, Yazdanshenas O, Knowlton BJ (2012) Age related differences in the neural substrates of motor sequence learning after interleaved and repetitive practice. Neuroimage 62:2007-2020. CrossRef Medline

Lustig C, Snyder AZ, Bhakta M, O'Brien KC, McAvoy M, Raichle ME, Morris JC, Buckner RL (2003) Functional deactivations: change with age and dementia of the Alzheimer type. Proc Natl Acad Sci U S A 100:1450414509. CrossRef Medline

Makris N, Goldstein JM, Kennedy D, Hodge SM, Caviness VS, Faraone SV, Tsuang MT, Seidman LJ (2006) Decreased volume of left and total anterior insular lobule in schizophrenia. Schizophr Res 83:155-171. CrossRef Medline

Margulies DS, Vincent JL, Kelly C, Lohmann G, Uddin LQ, Biswal BB, 
Villringer A, Castellanos FX, Milham MP, Petrides M (2009) Precuneus shares intrinsic functional architecture in humans and monkeys. Proc Natl Acad Sci U S A 106:20069-20074. CrossRef Medline

Mason MF, Norton MI, Van Horn JD, Wegner DM, Grafton ST, Macrae CN (2007) Wandering minds: the default network and stimulus-independent thought. Science 315:393-395. CrossRef Medline

McKiernan KA, Kaufman JN, Kucera-Thompson J, Binder JR (2003) A parametric manipulation of factors affecting task-induced deactivation in functional neuroimaging. J Cogn Neurosci 15:394-408. CrossRef Medline

McKiernan KA, D'Angelo BR, Kaufman JN, Binder JR (2006) Interrupting the "stream of consciousness": an fMRI investigation. Neuroimage 29: 1185-1191. CrossRef Medline

Oldfield RC (1971) The assessment and analysis of handedness: The edinburgh inventory. Neuropsychologia 9:97-113. CrossRef Medline

Pauwels L, Swinnen SP, Beets IA (2014) Contextual interference in complex bimanual skill learning leads to better skill persistence. PloS One 9:e100906. CrossRef Medline

Pauwels L, Vancleef K, Swinnen SP, Beets IA (2015) Challenge to promote change: both young and older adults benefit from contextual interference. Front Aging Neurosci 7:157. CrossRef Medline

Poldrack RA (2000) Imaging brain plasticity: conceptual and methodological issues-a theoretical review. Neuroimage 12:1-13. CrossRef Medline

Pruim RH, Mennes M, van Rooij D, Llera A, Buitelaar JK, Beckmann CF (2015) ICA-AROMA: a robust ICA-based strategy for removing motion artifacts from fMRI data. Neuroimage 112:267-277. CrossRef Medline

Ronsse R, Puttemans V, Coxon JP, Goble DJ, Wagemans J, Wenderoth N, Swinnen SP (2011) Motor learning with augmented feedback: modalitydependent behavioral and neural consequences. Cereb Cortex 21:1283-1294. CrossRef Medline

Sambataro F, Murty VP, Callicott JH, Tan HY, Das S, Weinberger DR, Mattay VS (2010) Age-related alterations in default mode network: impact on working memory performance. Neurobiol Aging 31:839-852. CrossRef Medline

Santos Monteiro T, Beets IAM, Boisgontier MP, Gooijers J, Pauwels L, Chalavi S, King B, Albouy G, Swinnen SP (2017) Relative cortico-subcortical shift in brain activity but preserved training-induced neural modulation in older adults during bimanual motor learning. Neurobiol Aging 58:5467. CrossRef Medline
Shea JB, Morgan R (1979) Contextual interference effects on the acquisition, retention, and transfer of a motor skill. J Exp Psychol Hum Learn Mem 5:179-187. CrossRef

Shea JB, Zimny ST (1983) Context effects in memory and learning movement information. In: Memory and control of action (Magill RA, ed), pp 345-366. Amsterdam: North-Holland.

Sisti HM, Geurts M, Clerckx R, Gooijers J, Coxon JP, Heitger MH, Caeyenberghs K, Beets IA, Serbruyns L, Swinnen SP (2011) Testing multiple coordination constraints with a novel bimanual visuomotor task. PloS One 6:e23619. CrossRef Medline

Smallwood J, Schooler JW (2015) The science of mind wandering: empirically navigating the stream of consciousness. Annu Rev Psychol 66:487518. CrossRef Medline

Smith SM (2004) Overview of fmri analysis. Br J Radiol 77:S167-175. CrossRef Medline

Tanaka S, Honda M, Hanakawa T, Cohen LG (2010) Differential contribution of the supplementary motor area to stabilization of a procedural motor skill acquired through different practice schedules. Cereb Cortex 20:2114-2121. CrossRef Medline

Woolley DG, Wenderoth N, Heuninckx S, Zhang X, Callaert D, Swinnen SP (2010) Visual guidance modulates hemispheric asymmetries during an interlimb coordination task. Neuroimage 50:1566-1577. CrossRef Medline

Woolrich MW, Jbabdi S, Patenaude B, Chappell M, Makni S, Behrens T, Beckmann C, Jenkinson M, Smith SM (2009) Bayesian analysis of neuroimaging data in FSL. Neuroimage 45:S173-186. CrossRef Medline

Wright D, Verwey W, Buchanen J, Chen J, Rhee J, Immink M (2016) Consolidating behavioral and neurophysiologic findings to explain the influence of contextual interference during motor sequence learning. Psychon B Rev 23:1-21. CrossRef

Wymbs NF, Grafton ST (2009) Neural substrates of practice structure that support future off-line learning. J Neurophysiol 102:2462-2476. CrossRef Medline

Zhang S, Li CS (2012) Functional connectivity mapping of the human precuneus by resting state fmri. Neuroimage 59:3548-3562. CrossRef Medline

Ziemann U, LönneckerS, Paulus W (1995) Inhibition of human motor cortex by ethanol. A transcranial magnetic stimulation study. Brain 118: 1437-1446. CrossRef Medline 